Editorial

\section{Retrosternal goiter mimicking asthma: A diagnostic challenge}

\section{Yiannakopoulou Eugenia*}

Department of Biomedical Sciences, Faculty of Health and Caring Sciences, University of West Attica, Athens, Greece

\section{Editorial}

Asthma is a chronic respiratory disease characterized by chronic airway inflammation. Common manifestations of asthma include wheezing, chest tightness, cough, shortness of breath. Diagnosis of asthma requires clinical documentation of respiratory symptoms, exacerbation of symptoms following exposure to triggers, as well as demonstration of expiratory airflow obstruction. Wheeze is a continuous sound, lasting longer than $0.25 \mathrm{~s}$ that is produced by oscillation of opposing airway walls [1,2]. Wheezing, although a typical symptom of asthma, can also be caused by other diseases. Apart from asthma, wheezing can be due to extra-thoracic upper airway obstruction, intrathoracic upper airway obstruction, lower airway obstruction.

Benign multimodal goiter is a common disease, that rarely causes upper airway obstruction. Retrosternal goiter should be taken into account the differential diagnosis of upper airway obstruction [3]. The respiratory symptoms of a retrosternal goiter may be masked for years due to the slow growth of the goiter. Patients commonly complain of respiratory symptoms if tracheal diameter is narrowed more than $50 \%$ from the normal size. Respiratory symptoms may be suddenly precipitated by spontaneous or traumatically induced bleeding into the substernal goiter, as well as by tracheal infections [4]. Clinical management of this condition is really challenging. Diagnosis is also not straightforward, as clinical suspicion is needed. There are cases of retrosternal goiter mimicking asthma that remain undiagnosed for many years. Retrosternal goiter should be taken into account in the differential diagnosis of patients diagnosed as suffering from asthma, and presenting no improvement despite medical therapy. In addition, it should be taken into account that sudden gland enlargement due to hormonal changes might lead to life threatening upper airway obstruction with clinical picture similar to bronchial asthma attack [5]. In a recent very interesting case report, the authors present a case of a pregnant woman in the second trimester who presented with an acute airway obstruction due to the enlargement of a retrosternal goiter [3].

\section{References} 663-673. 399-405.

\section{More Information}

*Address for Correspondence: Yiannakopoulou Eugenia, Department of Biomedical Sciences, Faculty of Health and Caring Sciences, University of West Attica, Athens, Greece, Tel: +00306978065409; Email: nyiannak@teiath.gr; nyiannak@uniwa.gr

Submitted: 14 November 2019

Approved: 09 January 2020

Published: 10 January 2020

How to cite this article: Eugenia Y. Retrosternal goiter mimicking asthma: A diagnostic challenge. Arch Asthma Allergy Immunol. 2020; 4: 001-002.

DOI: dx.doi.org/10.29328/journal.aaai.1001017

Copyright: ㄷ 2020 Eugenia Y. This is an open access article distributed under the Creative Commons Attribution License, which permits unrestricted use, distribution, and reproduction in any medium, provided the original work is properly cited

W) Check for updates

(.) OPEN ACCESS

Goiters are the more common masses of the superior mediastinum [6,7]. Commonly, retrosternal goiter is due to the extension in the thorax of a cervical goiter. However, rarely, it may represent primary disease due to the growth of ectopic thyroid tissue. In addition, retrosternal goiter may develop in patient submitted to thyroidectomy due to cervical multinodular goiter [8]. Although retrosternal goiters are commonly asymptomatic, symptoms may include dyspnea, stridor, hoarseness, dysphagia, superior vena cava syndrome, transient ischemic attacks, cerebral edema, Horner's syndrome, and thyrotoxicosis [4]. Diagnosis could be verified by neck and chest radiography, thorax CT and MRI. Chest radiography commonly shows a widened mediastinum with a superior mediastinal mass causing compression of the trachea as well as deviation of the trachea to the right. Mediastinal computed tomography reveals a mass that is extension of the thyroid gland. The presence of respiratory symptoms in a patient with retrosternal goiter is an indication for surgery. The majority of retrosternal goiters can be approached through a cervical approach $[9,10]$.

1. Loudon R, Murphy RL Jr. Lung sounds. Am Rev Respir Dis. 1984; 130 :

PubMed: https://www.ncbi.nlm.nih.gov/pubmed/6385790

2. Forgacs $P$. The functional basis of pulmonary sounds. Chest. $1978 ; 73$ :

PubMed: https://www.ncbi.nlm.nih.gov/pubmed/630938

3. Loo GH, Wan Mat WR, Muhammad R, Azman M. Obstructive retrosternal 
goitre mimicking severe bronchial asthma in pregnancy. BMJ Case Rep. 2019; 12.

PubMed: https://www.ncbi.nlm.nih.gov/pubmed/31383679

4. Mack E. Management of patients with substernal goiters. Surg Clin North Am. 1995; 75: 377-394.

PubMed: https://www.ncbi.nlm.nih.gov/pubmed/7747247

5. Mettam IM, Reddy TR, Evans FE. Life-threatening acute respiratory distress in late pregnancy. $\mathrm{Br} \mathrm{J}$ Anaesth. 1992; 69: 420-431. PubMed: https://www.ncbi.nlm.nih.gov/pubmed/1419458

6. Cagli K, Ulas MM, Hizarci M, Sener E. Substernal goiter: an unusual cause of respiratory failure after coronary artery bypass grafting. Tex Heart Inst J. 2005; 32: 224-227.

PubMed: https://www.ncbi.nlm.nih.gov/pubmed/16107122
7. Vadasz P, Kotsis L. Surgical aspects of 175 mediastinal goiters. Eur $\mathbf{J}$ Cardiothorac Surg. 1998; 14: 393-397.

PubMed: https://www.ncbi.nlm.nih.gov/pubmed/9845144

8. Galiñanes EL, Caron N. Remnant large retrosternal thyroid goiter after thyroidectomy. Am Surg. 2012; 78: E222-223. PubMed: https://www.ncbi.nlm.nih.gov/pubmed/22472381

9. Doulaptsi M, Karatzanis A, Prokopakis E, Velegrakis S, Loutsidi A, et al. Substernal goiter: Treatment and challenges. Twenty-two years of experience in diagnosis and management of substernal goiters. Auris Nasus Larynx. 2019; 46: 246-251.

PubMed: https://www.ncbi.nlm.nih.gov/pubmed/30055961

10. Torres A, Arroyo J, Kastanos N, Estopá R, Rabaseda J, et al. Acute respiratory failure and tracheal obstruction in patients with intrathoracic goiter. Crit Care Med. 1983; 11: 265-266.

PubMed: https://www.ncbi.nlm.nih.gov/pubmed/6831895 